\title{
A Experiência num Campo Desconhecido: A Instituição Policial Entendida por uma Estudante de Psicologia
}

Experience in an unknown field: The police institution considered as a human surrounding

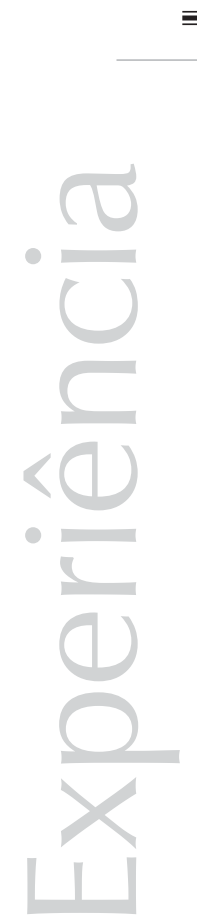

Denise

Fernanda de Lima Cavalcanti

Universidade

Bandeirante de São Paulo

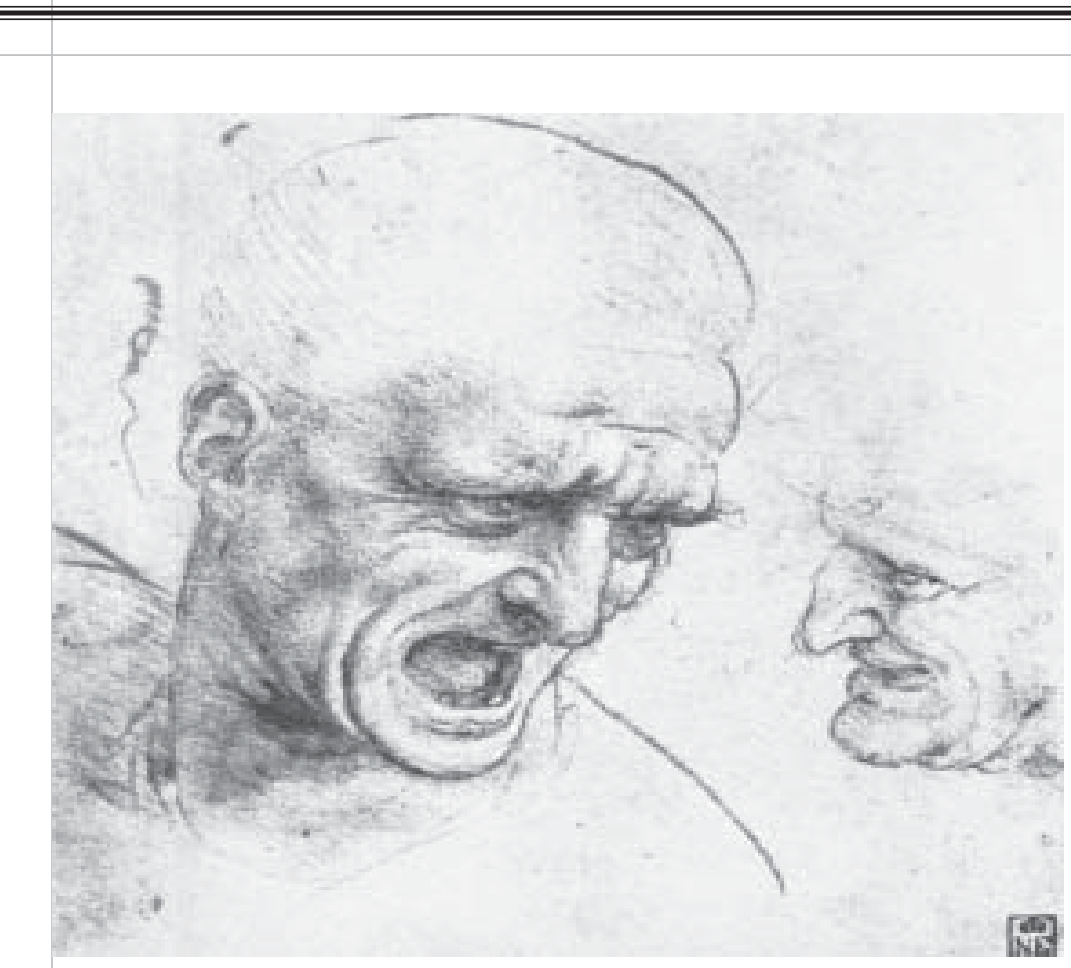


Resumo: O presente artigo pretende demonstrar minha experiência de estágio na disciplina de Psicologia do trabalho, realizado no ano de 2004, numa instituição policial de São Bernardo do Campo. O artigo é uma reflexão sobre a equipe de policiais que acompanhei a partir das observações e de uma análise crítica a respeito dos processos psicológicos nela envolvidos, que foi refletida junto à instituição e aos policiais. O estágio foi baseado na questão da saúde mental do trabalhador, procurando demonstrar os novos olhares da Psicologia sobre essa instituição e o amplo campo de atuação do psicólogo.

Palavras-chave: condição e organização do trabalho na polícia civil, Psicologia do trabalho e saúde mental do trabalhador.

Abstract: The present article intends to demonstrate my apprenticeship experience in the subject Work Psychology during the year 2004 in a police institution of São Bernardo do Campo. The article is a reflection about the policemen group that I accompanied, starting from the observations and a critical analysis about the psychological process inside it, which was reflected on the institution and the policemen. The apprenticeship was based on the the worker's mental health, trying to demonstrate the new trends of Psychology on this institution and the wide field of the psychologist's work.

Key words: condition and organization of the civil police work, Work Psychology and mental health of the worker.

\section{Diretrizes do trabalho em campo}

O objetivo principal foi analisar aspectos referentes à Psicologia do trabalho quando inseridos na polícia civil e sua relação com a saúde mental do trabalhador e os aspectos que nela estão envolvidos (organização, condição de trabalho e estratégias defensivas). Serão analisados 'pontos - chave' que foram observados durante minha permanência na instituição e que podem ser utilizados como subsídios para novas formas de atuação do psicólogo mediante essa temática.

\section{Diretrizes do trabalho policial}

Para que melhor entendam a problemática deste assunto, torna-se necessário fazer referência à emenda do Projeto de Lei no 6.690, de 2002, art. 4으, que ressalta as funções e atribuições dos policiais civis; são elas:

Planejar, coordenar, dirigir e executar as ações de polícia judiciária;
- Executar, com exclusividade, ressalvados nos crimes militares e nas atribuições da polícia federal, a apuração de infrações penais e as funções de polícia judiciária;

- Organizar e executar os serviços de identificação civil e criminal;

- Organizar, executar e manter os serviços de registro, cadastro, controle e fiscalização de armas, munições e explosivos, na forma de legislação federal específica;

- Realizar ações de inteligência destinadas à instrumentação do exercício de polícia judiciária e de apuração de infrações penais, na esfera de sua competência, observados os direitos e garantias individuais;

- Realizar correições e inspeções, em caráter permanente ou extraordinário, na esfera de sua competência; 
É interessante citar algumas representações do meu papel para eles, pois, ora eu era a "caçadora de loucos" (sic), ora "psicóloga da corregedoria" (sic), que estava ali para avaliar cada um deles, e outrora "avaliadora do trabalho e dos comportamentos individuais"(sic).
- Realizar pesquisas técnico-científicas, estatísticas e exames técnicos relacionados com as atividades da polícia judiciária;

- Ter acesso aos bancos de dados existentes nos órgãos de segurança pública, relativos à identificação criminal, armas, veículos e objetos, observado o disposto no inciso $\mathrm{X}$ do art. $5^{\mathrm{O}} \mathrm{da}$ Constituição Federal.

São atribuições que seriam de fácil realização se houvesse políticas adequadas e melhores condições de trabalho, podendo assim, quem sabe, fazer com que esses profissionais conseguissem realizar de melhor forma suas atividades.

\section{O olhar de uma estagiária de Psicologia na instituição: polícia}

Mediante os grandes índices de violência cometida por policiais no Estado de São Paulo, e correlacionando-os com as funções descritas nas diretrizes do trabalho policial, ao mesmo tempo em que, observando as condições e sofrimentos envolvidos no trabalho policial e sua relação atual, caótica, com a sociedade, tive o interesse de melhor conhecer esse ambiente profissional cercado por duas vertentes, a sociedade e a lei.

No princípio, algumas perguntas angustiantes ficavam em minha mente, e eu me questionava: Qual seria meu papel dentro da instituição? Em qual posição eles me colocariam? Quais as expectativas que seriam postas em mim? Quando as dúvidas surgiam, procurava lembrar as diretrizes e objetivos do estágio, que eram conhecer a dinâmica, condição e organização do trabalho dessa instituição e correlacioná-las com aspectos psicossociais dos policiais civis, em específico, com os integrantes do grupo que acompanhei, grupo esse composto de aproximadamente 55 policiais.
As primeiras visitas foram destinadas a conhecer as equipes, e, para tanto, foi necessário conversar com os profissionais e observar situações de trabalho. Porém, devido aos horários diferenciados, não foi possível conhecer todos os profissionais, mas sempre procurei deixá-los a par dos encontros com avisos no mural, e, assim, todos devem ter sabido da realização do estágio e de seu objetivo.

No início do estágio, percebi um mal-estar, de ambas as partes, em relação a minha presença; era nítido, pois, muitas vezes, quando eu chegava, alguns mudavam de assunto, outros de repente ficavam quietos e outros preferiam retirar-se da sala; tudo acontecia de modo muito discreto, como se não quisessem que eu percebesse tais incômodos. Quando minha presença, meus recados, tornaram-se constantes, minhas explicações sobre o estágio foram sendo esclarecidas, e o contato foi maior a ponto de outros investigadores começarem a aproximar-se, e acredito que tenha conseguido desmitificar algumas fantasias referentes a minha presença. Não afirmo que todos tenham se aproximado, porque isso não aconteceu. Mesmo no término do estágio, alguns evitaram conversar comigo, mesmo quando fui conversar com eles sobre os pontos principais que pude observar, numa linguagem não técnica, mas de fácil entendimento.

É interessante citar algumas representações do meu papel para eles, pois, ora eu era a "caçadora de loucos" (sic), ora "psicóloga da corregedoria" (sic), que estava ali para avaliar cada um deles, e outrora "avaliadora do trabalho e dos comportamentos individuais" (sic). Em todas as visitas, as palavras: loucos, doidos e loucura foram mencionados e interpretados com os próprios para que, dessa forma, pudéssemos entender as representações dessas palavras. Mesmo que dissessem isso num clima de 'brincadeira' e 'descontração', como eles mesmos ressaltavam, essas figuras 
representativas eram preocupantes e manifestadas no discurso de cada um, sendo, assim, considerado o discurso do grupo, como se eu estivesse ali para julgar as formas de trabalho, as decisões tomadas ou avaliar cada um deles de forma individualizada, o que não era verdade.

Com o decorrer do estágio, entrevistas foram realizadas com o intuito de melhor conhecer as formas de trabalho, o histórico profissional, a satisfação com o grupo, o que os policiais pensam a respeito do trabalho da equipe, expectativas futuras, desejos, frustrações e decepções referentes ao cotidiano. Muitas entrevistas foram realizadas de modo informal, enquanto tomavam café, devido ao pouco tempo que permaneciam na base, e, mesmo assim, deram subsídios suficientes para as análises realizadas.

Muitos aspectos considerados positivos foram observados, interpretados e analisados em relação aos policiais civis daquele grupo: a relação de confiança estabelecida entre as equipes, a liberdade de expressão, mesmo nas relações entre os diferentes níveis hierárquicos, o respeito entre todos, o desejo de desmitificar a imagem do policial na sociedade, o desejo de crescimento profissional e pessoal e a busca de melhorias para as condição e organização de trabalho. Cabe aqui ressaltar que, mesmo que passem a maior parte do tempo juntos, os integrantes do grupo possuem divergências de opinião, o que não prejudica a realização das atividades e pode ser considerado positivo, pois mostra que cada um possui identidade, valores e pensamentos próprios.

A integração que é realizada quando um novo membro compõe a equipe é feita no dia a dia de trabalho, e, aos poucos, esse 'novo integrante' irá conhecer tanto a equipe específica onde irá atuar como também todos os que compõem a instituição. Percebi a necessidade de esse novo integrante ter a oportunidade de conhecer a história do grupo, os principais trabalhos, os objetivos reais, saber os direitos e deveres dos policiais. No que se refere ao conhecimento de nível pessoal, isso é realizado constantemente e diariamente entre as equipes; a cada história, a cada risada, eles vão intensificando os laços de confiança e amizade, atitudes que aumentam a satisfação do 'novato', pois este se sente acolhido pelas equipes e também serve de 'termômetro' para saber se realmente é naquela equipe, e refirome a todos os que compõem a base, que ele gostaria de atuar.

Os policiais apresentam-se como uma equipe que, mesmo "mergulhada" num grande sistema burocrático que, muitas vezes, os impede de realizar algumas averiguações, na ausência de recursos, tentam realizar com eficiência os trabalhos e esperam, pela realização destes, serem reconhecidos.

O ambiente de trabalho, mesmo envolto nas pressões do dia a dia, na burocracia e na escassez de recursos, pode ser considerado agradável e intenso. Agradável, no sentido de que, quando estão reunidos, procuram não apenas conversar sobre o trabalho mas também a respeito da vida pessoal, procurando manter sempre o bom humor, e intenso, no sentido de que não há rotina dentro da base; ao mesmo tempo em que 'descansam', pensam nas próximas investigações e nas que ainda estão em andamento.

A satisfação no trabalho, pelas entrevistas realizadas, formais ou não, indica que há um grau de satisfação na realização deste, mesmo com algumas dificuldades que os próprios policiais mencionam: baixa remuneração, cansaço físico e, principalmente, mental, burocratização, falta de autonomia, escassez de recursos materiais, número insuficiente de policiais para compor as equipes e operações realizadas para fins políticos. Esses fatores, apesar de serem citados pela maioria dos
O ambiente de trabalho, mesmo envolto nas pressões do dia a dia, na burocracia e na escassez de recursos, pode ser considerado agradávele intenso. 
Uma atividade que envolve riscos de não saber quando se levará um tiro, de estar constantemente exposto ao risco de morte ou de ver o colega de trabalho ferido,

leva-nos a pensar que as pessoas que a realizam devem, realmente, ter algo de 'louco' dentro de si, daí o referido medo. policiais e serem considerados, por mim, fatores desmotivantes, fazem com que outros continuem motivados a realizar todos os trabalhos para os quais são solicitados, pois possuem a esperança de obter, algum dia, melhoria, tanto nas condições como na qualidade do trabalho.

\section{O prazer e o sofrimento no trabalho}

Como estagiária de Psicologia da instituição, coube-me indicar os pontos a serem refletidos e desenvolvidos dentro da equipe e da instituição no sentido de melhoria da qualidade do trabalho e da saúde mental do trabalhador, buscando alternativas junto a eles para propiciar essas melhorias. Com o término do estágio, posso dizer que, de certa forma, vivenciei o limite profissional para a realização dessa melhoria.

O primeiro ponto-chave que considero de importância fundamental para pensar novas práticas de intervenção é a questão do adoecer psíquico e, indo além, o medo de estar ou ficar "louco" devido às tarefas diárias. Percebese esse tipo de medo em relação aos perigos a que estão expostos, situações relacionadas às condições de trabalho e às formas de atuação, fatores que agem de modo 'enlouquecedor'.

Levando em consideração a pesquisa "Missão Investigar: entre o Real e o Ideal de Ser Policial", realizada por Maria Cecília de Souza (2003) no Estado do Rio de Janeiro, com 1458 policiais distribuídos em 3 estratos: administrativo (438), técnico (487), e, de maior relevância para este artigo, operacional (533), quando a situação cotidiana gera conseqüências físicas e psíquicas para os policiais civis operacionais, esse sofrimento está na proporção de: $48,2 \%$ sentese nervoso, tenso ou agitado; $37,4 \%$ dorme mal; 33,3\% sente-se incapaz de desempenhar papel útil em sua vida; $31,5 \%$ sente-se triste ultimamente; $24,3 \%$ tem dificuldades para realizar com satisfação as atividades diárias;
$8,7 \%$ tem dificuldades no serviço; $5,4 \%$ sentese uma pessoa inútil e 3,4\% tem tido a idéia de acabar com a própria vida.

Posso considerar que as características encontradas na instituição policial do Rio de Janeiro, em muitos aspectos, estão interligadas com as observações por mim desenvolvidas; posso dizer que esses mesmos fatores foram apresentados por muitos deles, apenas o item 'acabar com a própria vida' não foi mencionado. Esse tema não era muito citado pelos mesmos, pois conheceram e foram amigos de policiais civis que, não agüentando a situação cotidiana, suicidaram-se, e estes preferiam não comentar o assunto, como se fosse algo secreto e não revelado e / ou comentado.

Uma atividade que envolve riscos de não saber quando se levará um tiro, de estar constantemente exposto ao risco de morte ou de ver o colega de trabalho ferido, leva-nos a pensar que as pessoas que a realizam devem, realmente, ter algo de 'louco' dentro de si, daí o referido medo.

Outro dado da pesquisa de Maria Cecília revela que policiais civis operacionais sofrem com os riscos de agressões na proporção de $99,2 \%$, por tiro; 89,2\%, por risco físico; 80,3\%, por arma branca; $64,5 \%$, por agressões psicológicas, e $46,4 \%$, por seqüestro. Considera-se que $92,5 \%$ dos operacionais correm riscos, e alguns escondem a própria identificação de policial omitindo sua profissão por questão de sobrevivência. Sendo assim, podemos considerar como maior preocupação não somente o risco por agressões físicas mas principalmente as agressões psicológicas, que chegam a $54,5 \%$, o que demonstra a importância de trabalhos sobre a saúde mental dos policiais.

Por conta disso, o grupo lança mão de mecanismos de defesa coletivos - estratégias coletivas de defesa, que a psicodinâmica do trabalho identificou nas relações dos membros 
de um grupo; elas contribuem de maneira decisiva para a coesão do coletivo, pois o trabalho não é só uma atividade mas também um viver: viver a experiência do medo, da pressão, da situação e do sofrimento para tentar gerenciar seu sofrimento psíquico decorrente da experiência do trabalho, visando à clivagem entre corpo, pensamento e psiquismo, de maneira a continuar trabalhando no máximo da descompensação psíquica e da saúde mental.

Tentando evitar o medo de enlouquecer e o contato com pensamentos de 'loucura', o grupo que observei criou uma dinâmica de defesa grupal que é a risada: RIR de algumas situações de perigo que vive constantemente ou rir do colega que procura conversar sobre algum tema que o está angustiando naquele momento. Uma das soluções que agiria de forma interventiva seria a criação de espaços fora do ambiente policial para que pudessem dialogar sobre os sentimentos em relação ao trabalho e sobre como isso os afeta, não somente como policiais. A formação de grupos operativos ou a própria psicoterapia seria uma excelente forma de trabalharem tais questões no que tange ao aspecto profissional / pessoal.

Com as observações, posso pontuar, e não afirmar, ainda, que o grupo desafia o próprio medo, seja em operações arriscadas de combate seja no aumento do ritmo de trabalho para evitar passar o tempo 'pensando' nos sentimentos relacionados ao trabalho que realizou, justamente para que a agressividade, a frustração contra a sociedade e a própria loucura não tomem conta de sua vida.

Dejours (1991) ressaltou que o explorado pela organização do trabalho não é o sofrimento em si, mas principalmente os mecanismos de defesa utilizados contra esse sofrimento. No caso desse grupo, o fato de ficar muito tempo longe da família em situação de risco e a frustração de não conseguir atender toda a população que os aciona, gera ansiedade (que tentam controlar com o cigarro ou com grande ingestão de alimentos), vontade e o desejo de tornar a sociedade segura, mostrando, dessa forma, o quão inseguros eles se sentem, aliás, o quão insegura a sociedade se sente, tornando-se, a cada dia, mais neurótica em relação à segurança.

Se o grupo passa a maior parte do seu tempo diário no trabalho, reprimindo as frustrações e as angústias pertencentes a este, onde são depositados a frustração, tensão e o nervosismo que são "proibidos" de sentir? O tempo tornase escasso para as relações amorosas, então, onde vão ser depositados todos os desejos, anseios e vontades libidinais pela pessoa amada? Se todos querem a resposta mais simples, tudo é depositado, mesmo que inconscientemente, no trabalho / na instituição.

O desconhecimento de tais sentimentos gera a "ignorância" sobre si mesmo, o que, em conseqüência, aumenta o medo (do que não conhecem neles mesmos), e o medo, para ser "escondido", gera mais trabalho. Gerar mais trabalho traz conseqüências não somente físicas para o indivíduo mas também cansaço mental, o que pode, para eles, ser prejudicial e definitivo em algumas operações desempenhadas, colocando o grupo em maior risco.

Segundo Dejours (1999), as estratégias coletivas de defesa agravam o risco de exposição ao perigo, ao invés de limitá-lo. Sendo assim, as condutas ansiosas para a resolução e o desafio ao risco também podem ser consideradas uma tentativa de domínio simbólico do medo, pois, quanto mais perigosos forem os casos, mais o medo poderá ser controlado e / ou desafiado. Pode-se considerar que o medo serve como forma de produtividade, pois sempre estarão atentos, e, quando o medo é coletivo, cria-se uma verdadeira teia de eficiência. Isso pode ser demonstrado naqueles que não conseguem desligar-se do trabalho quando viajam, quando vão ao cinema, ou mesmo quando estão em casa.
$\mathrm{O}$

desconhecimento de tais sentimentos gera a "ignorância" sobre simesmo, o que, em conseqüência, aumenta o medo (do que não conhecem neles mesmos), e o medo, para ser "escondido", gera mais trabalho. 
O perigo extremo vivenciado no cotidiano desse grupo faz com que se tornem produtivos durante 24 horas por dia, trabalhando ou estando de folga, fato que não deveria ocorrer, mas podemos culpá-los? Todos os dias estão em operações onde vêem vítimas que morreram por 'banalidades', enfrentam pessoas que, passando na rua, não levantam suspeitas, vão a lugares que nunca imaginaram conhecer ou existir; talvez seja normal que tenham mais cuidado ao sair. Mas qual o limite da segurança e da exploração do sofrimento psíquico? O grupo, não tendo conhecimento dessa dinâmica psíquica, acaba comportandose como policial 24 horas por dia, como se isso fosse algo obrigatório, e que dele fosse exigido. Tal fato é visto por eles como decisório, partindo do ponto de que eles sabem o que acontece diariamente nas ruas; sendo assim, estão em constante alerta para que não aconteça nada de pior com ninguém, principalmente com as pessoas com as quais têm um vínculo afetivo.

Outra questão a ser pontuada é a questão da falta de lazer ou de atividades que não estejam relacionadas ao trabalho, fator a ser considerado dentro da profissão e suas conseqüências para os trabalhadores. Considerando a carga horária e as outras formas de ganhos para aumentar a renda mensal (os chamados bicos), o tempo livre torna-se escasso e raro, e isso acaba trazendo para o grupo assuntos pessoais que o preocupa mais do que o próprio trabalho, pois eles sofrem pressões domésticas das(os) companheiras(os), que exigem maior presença e, ao mesmo tempo, as dificuldades salariais os impossibilitam de estar junto da família; é comum que parte da equipe ou seja solteira ou esteja em processo de separação ou se queixe das intensas discussões com a (o) parceira (o), e, para alguns, a "culpa", não em sua totalidade, mas em grande parte, está no trabalho. Por esse motivo, podemos pensar no trabalho policial e nos reflexos que isso traz para a família e para sua relação com ela. Acredito que exista uma perda de identidade e, nesse caso, a mantida é, especialmente, a de policial, havendo uma dificuldade em dissociar o que é vida profissional do que é vida pessoal.

Um outro ponto-chave a ser considerado é a questão da desvalorização profissional, principalmente no âmbito financeiro, porque, como já é sabido, muitos deles fazem bico para conseguirem renda mensal que sustente a casa e os filhos. Sempre afirmaram que ganhar pouco significa não ser reconhecido pelo trabalho e esforço, porém, apesar da desvalorização profissional de ordem financeira, todos gostam de trabalhar na polícia, tanto pelo ambiente agradável, pelas amizades como pelas pessoas que um dia puderam ajudar e correlacionam isso diretamente com a auto-estima profissional. A questão salarial não é o único fator de reivindicação; desejam também mudanças no que tange à condição e organização do trabalho.

Segundo Jackson, J.; Codo, W; e Haruyoshi, A. (1995),

"A temática do trabalho vem exigindo estudo aprofundado do universo concreto, quotidiano, dos trabalhadores reais, construtores de si e do mundo, diferenciados, inseridos em distintas categorias profissionais, por sua vez inseridas em ramos diferenciados de produção ou prestação de serviços. O trabalho tem sido entendido como simples, parcializado, tomado por algum de seus elementos constitutivos. Mas o trabalho é outra totalidade complexa desafiando entendimento, móvel sobre móvel, gerando subjetividade, relações sociais, identidade, produtos, mercadorias: no ventre dos negócios. O desafio atual é dimensionar essa complexidade, reconhecer os valores sociais que o trabalhador gera, reconhecer que o trabalho desvalorizado engendra nova natureza de valores sociais. O trabalho desvalorizado (expansão do trabalho morto, trabalho incorporado nas máquina; expansão do trabalho incapaz de gerar relações sociais; expansão da especulação), desvaloriza o trabalhador, 
fragilizando-o de modo irrecuperável, mesmo na presença de 'ambiente saneado' e de 'perfeitos ajustes anatômicos corpo / instrumento'" (p. 86).

A valorização do trabalho é fator primordial para a auto-estima do trabalhador, principalmente porque é vista como mediadora de identidade, e cria-se a ilusão de que, fazendo o grupo ser recompensado financeiramente, irá gerar uma sensação de valorização profissional. Partindo do princípio que o trabalho ocupa na vida dos indivíduos um lugar decisório, e a partir deste ele é visto como um integrante da sociedade, deve-se pensar na conseqüência psíquica de um trabalho que é tão cobrado numa estrutura rígida, que exige uma obediência às regras impostas, onde a opinião do grupo e sua subjetividade grupal e individual nem sempre são levadas em conta, e, sim, confiscadas pela instituição policial. O que deve existir, na realidade, é a valorização da subjetividade dos indivíduos desse grupo e o entendimento das reais necessidades psicológicas de cada um. Para isso acontecer, suas vozes necessitam ser ouvidas, não somente por nós, psicólogos, mas também pelas autoridades que possuem o real poder de decisão.

Se, por um lado, os policiais "lutam" pela melhoria financeira, em contrapartida, a instituição exige maior produtividade, independentemente dos ganhos financeiros; em conseqüência, a sensação de inutilidade do ponto de vista pessoal / profissional aumenta, porque acreditam que sua vida é muito valiosa para tão poucos ganhos, mas precisam ser eficientes porque é a profissão que escolheram. Para eles, não é fácil entender como conseguem ser bons policiais, e, muitas vezes, "não podem ser" bons maridos e pais. Mesmo considerando que o trabalho não deva interferir nessa concepção do que é ser bom pai ou marido, admitem que a frustração e insatisfação profissional influenciam no dia a dia familiar.
Para obter essa valorização, um mecanismo inconsciente, ou não, é transformar o que seria um objetivo primário em objetivo secundário, ou seja, a cada feito considerado heróico, o que entra em primeiro plano é a necessidade de ser reconhecido, pela sociedade, como um grupo cuja função é de extrema importância para a segurança e bem-estar da sociedade. Em segundo plano, fica o objetivo de seu trabalho, proteger a sociedade independentemente de serem reconhecidos ou não. Ser reconhecido em primeiro plano faz com que as questões salariais se tornem, naquele momento, menos importantes para o grupo; por isso, a cada grande apreensão, a mídia é chamada a fim de registrar tal momento e, assim, melhorar tanto a imagem que eles têm de si próprios como a imagem que a sociedade tem deles. Incorretos?

Ao mesmo tempo, a questão de ordem familiar também se torna um objetivo primário dentro do ambiente de trabalho; em diversas conversas sobre o cotidiano policial, muitas vezes comentavam ou desviavam os assuntos para as questões de ordem familiar e sobre como é difícil manter uma família sendo policiais e com salário desmotivante. Incorretos, novamente?

\section{Em relação às duas questões, impostas, pode-se julgá-los? Pensem a respeito, mas cuidado com o maniqueísmo.}

Numa sociedade em que os profissionais da área de segurança pública são envolvidos em escândalos (envolvimento com traficantes, recebimento de propina, roubos), dos quais, como resultado, a classe policial como um todo sofre as conseqüências, de uma parte dessa categoria profissional, a população torna-se incrédula frente à ação policial e à da Justiça. Porém, mesmo com essa situação, a maioria do grupo observado revela sentir prazer no trabalho, tanto pelo clima agradável existente na base como pelas amizades que fizeram durante anos de profissão. Porém, cabe a nós, 
Quando nós aparecemos com nossa proposta de observação e intervenção, dentro de nossas possibilidades, acabamos gerando expectativas e tensão sobre o que era esperado do nosso papel e, o mais importante, sobre o que esperóvamos de nós mesmos dentro daquela instituição. psicólogos, questionarmos e analisarmos as relações dentro da instituição, demonstrando, intervindo e propiciando melhores condições psíquicas de trabalho, para que a saúde psíquica do trabalhador seja preservada dentro do ambiente de trabalho e na sociedade neurótica e caótica em que vivemos. Não caberá a nós, novamente, julgar se tais condutas são boas ou más, mas, sim, avaliar como isso influencia o indivíduo no grupo ao qual está inserido.

Tendo em vista o que foi pontuado em relação à 'loucura' do trabalho, identidade policial exigida 24 horas, (des)valorização profissional, subjetividade que é confiscada pela instituição, objetivos que são distorcidos para a sociedade, pode-se considerar que os policiais devem ter realmente algo de loucos dentro de si para aceitar tais condições. O sintoma de um indivíduo é, nesse caso, o sintoma do grupo como um todo, o que proporciona o surgimento, inconsciente ou não, de mecanismos de defesa coletivos, tornando-se mais fácil acobertar o problema.

Dois caminhos podem ser seguidos pelo indivíduo: o primeiro é fazer parte desse mecanismo coletivo de defesa, que podemos chamar de não dito, e, com isso, optar por não encarar as questões sobre relações e sentimentos profissionais / pessoais ou optar pelo segundo caminho, que é o de ser excluído do grupo quando se tenta introduzir o tema que o angustia; com isso, terá os companheiros rindo, para se protegerem.

Quando nós aparecemos com nossa proposta de observação e intervenção, dentro de nossas possibilidades, acabamos gerando expectativas e tensão sobre o que era esperado do nosso papel e, o mais importante, sobre o que esperávamos de nós mesmos dentro daquela instituição.

Temos de estar atentos para os papéis que nos são impostos e quais as reais possibilidades de modificação que o grupo está disposto a realizar, já que alguns papéis e discursos estão cristalizados, e, assim, apontar a necessidade de proteção à singularidade, individualidade e subjetividade de cada um dentro do grupo.

Como ressaltei no início, nosso papel, dentro das instituições, tem um limite difícil de ser encarado e torna-se, algumas vezes, frustrante, fazendo com que duvidemos da nossa própria capacidade profissional; porém, devemos estar atentos a tais sentimentos durante nossas pesquisas, pois podem ser fruto de uma "contaminação" institucional que faz com que pensemos em conceitos como o de bom ou mau, rotulando e julgando, o que não pode acontecer. Quando introjetamos essas "culpas" de não poder melhorar a vida dessas pessoas, os inconscientes se comunicam, e, a partir daí, a busca por melhorias acaba falhando e desmotivando a todos, porque acreditam que não adianta lutar, pois nunca haverá melhora. Esse grupo em específico, ou melhor, algumas pessoas do grupo encontram-se mobilizadas para um trabalho psicológico (individual ou grupal), enquanto alguns reconhecem a necessidade de apoio psicológico pelo trabalho que realizam e pelo ambiente em que vivem. Outros ainda possuem o discurso sobre essa problemática cristalizada e vêem quaisquer soluções como impossíveis para esse cotidiano. Outros aspectos, relacionados às observações, poderiam ser discutidos e analisados psicologicamente de modo mais profundo, porém alguns pontos devem ser mais bem observados, discutidos e analisados antes que alguma palavra seja dita. Não quis aqui tomar algum partido, apenas pontuo a importância da questão da intervenção na instituição policial a fim de melhorar a qualidade de vida desses que arriscam as vidas todos os dias em prol de uma sociedade mais segura e um país melhor. A partir do que foi compartilhado, acredito ser fundamental um novo olhar para o trabalho policial, sendo esse campo abrangente para a prática do psicólogo, porque os policiais, sejam civis, militares ou outros, sofrem com o impacto de seu trabalho, tanto na esfera da saúde física, psíquica como na familiar e social. 
Denise Fernanda de Lima Cavalcanti

Graduada em Psicologia pela Universidade Bandeirante de São Paulo - Uniban - em dezembro de 2004. Desenvolveu estágio supervisionado de Psicologia do trabalho, no ano de 2004, na polícia civil de São Bernardo do Campo.

Email:deniseflc@hotmail.com R: Afonso Furtado de Mendonça, 200 - Jd. Silvina

São Bernardo do Campo, S.P

Cep: 09791-000Tel.: (11) 7161-6044 (cel.)

Recebido 01/02/05 Reformulado 05/10/05 Aprovado 12/11/05

BRASIL. Emenda - Projeto de Lei no 6.690, de 2002. Estabelece as normas gerais e de organização, garantias, direitos e deveres dos policiais civis e as normas gerais de organização, efetivos, material bélico, garantias, convocações e mobilização das políticas militares e corpos de bombeiros militares dos Estados, do Distrito Federal e dos Territórios. CONGRESSO NACIONAL, 2002.

CODO, Wanderley; SAMPAIO, José Jackson C; HITOMI, Alberto H. Saúde Mental e Trabalho: um Modelo de Investigação. In Codo, Wanderley \& Sampaio, José J. C. Sofrimento Psíquico nas Organizações: Saúde Mental e Trabalho. Rio de Janeiro: Vozes, 1985, pp. 85-109.
DEJOURS, Chistopher. A Loucura do Trabalho: um Estudo de Patologia do Trabalho. 4eed. São Paulo: Cortez, 1991.

DEJOURS, Chistopher. A Banalização da Injustiça Social. 4ª ed. Rio de Janeiro: Editora FGV, 2001.

MINAYO, Maria Cecília S. \& SOUZA, Edinilsa Ramos. Missão Investigar: entre o Ideal e a Realidade de Ser Policial. Rio de Janeiro: Garamond, 2003.

MINAYO, Maria Cecília S. \& SOUZA, Edinilsa Ramos. Missão Investigar: Entre o Ideal e a realidade de ser Policial. Rio de Janeiro: Garamond, 2003. (fonte: III Seminário de Saúde do Trabalhador - SESAT, 2003).
Referências 